\title{
Transformation of cassava into Bêdê
}

\author{
Bouatenin Koffi Maïzan Jean-Paul*, Kouame Kohi Alfred, Coulibaly Wahauwouele \\ Hermann, Tanoh Ahou Edwige, Aka-Gbezo Solange and Dje Koffi Marcellin
}
Department of Food Sciences and Technology, Laboratory of Biotechnology and Food Microbiology, University Nangui Abrogoua, Abidjan, Côte d'Ivoire

*Corresponding author

\section{A B S T R A C T}

\section{Keywords \\ Cassava roots, Sweet variety, Cassava processing, bêdê \\ Article Info \\ Accepted: \\ 20 August 2020 \\ Available Online: \\ 10 September 2020}

The objective of this work was to promote bêde, which is a food made from the roots cassava in Côte d'Ivoire. To do this, the process of transformation of cassava into bêdê was monitored in order to establish a production diagram for bêê. It emerged from this observation that the processing of cassava into bêdê covers a combination of steps including washing of the sweet variety roots, retting, pressing, sieving, drying and steaming. At the end of all these operations a slightly yellow product with a lactic taste called bêe is obtained. The preparation of bêe is very long and laborious.

\section{Introduction}

In Côte d'Ivoire, the processing of cassava results in several foods including gari, fùfù, placali, attiéké and bêdê...etc. (N'Zué et al., 2013; Yéboué et al., 2017). Among these dishes, bêde is the least known in Côte d'Ivoire. It is the final product of a long and tedious wet processing of the reddened roots which includes several operations such as peeling, cutting, washing, retting, pressing, sifting, drying and steaming.

The bêe is a yellow semolina, with grains that are not very moist, compact and characterised by a sour taste. It is consumed exclusively within the family by the Agnis and Baoulé people living in Côte d'Ivoire in times of famine.

Today, bêdê is abandoned in favour of attiéké because of a laborious and too long transformation process. With the aim of enhancing the value of this endangered food, this work is part of a process of building knowledge of the different stages in the transformation of cassava into bêdê in order to facilitate its expansion on a national and international level. 


\section{Materials and Methods}

The study material consists of sweet cassava root taken from a bêdê producer.

\section{Monitoring the process of transformation cassava into bêdê}

The monitoring of production involved a producer of bêdê. The purpose of the followup was to observe the processor throughout the preparation of the bêdê and to establish a production diagram for the bêdê. Thus, work methods, hygiene practices and processing procedures were carefully identified.

\section{Results and Discussion}

Bêdê is a food made from the roots of cassava rouie. In the past, bêdê was eaten during the lean season and nowadays only people of three ages know of its existence. Furthermore, bêdê is consumed by the Agni and Baoulé peoples, nowadays abandoned to the attiéké profile because of its very long transformation process. Its preparation covers a combination of stages including washing the roots, retting, pressing, sieving, drying and steaming (Figure 2).

For the preparation of bêde, roots of sweet varieties are used because they soften easily and give a pleasant taste to the food. Next, the roots are peeled and cut into pieces of about 5 $\mathrm{cm}$ with a knife to facilitate softening during retting and washed well to remove various impurities and reduce the microbial load (Figure 3). These peeling, cutting and washing operations are also observed during the production of several cassava-based foods such as attieké, gari and cassava flour by Sotomey et al., (2001); FAO, 2012; GERES, 2013.

The peeled, cut and washed cassava roots are then immersed in water in a hermetically sealed container (canary, pot...) for 8 days, this operation is called retting (Figure 4). According to Louembé et al., (2002), cassavabased foods obtained after retting, allows the detoxification and softening of the cassava roots as well as the improvement of the organoleptic characteristics, in particular, the taste, smell and texture of the food.

Fig.1 Fresh cassava roots of the sweet variety

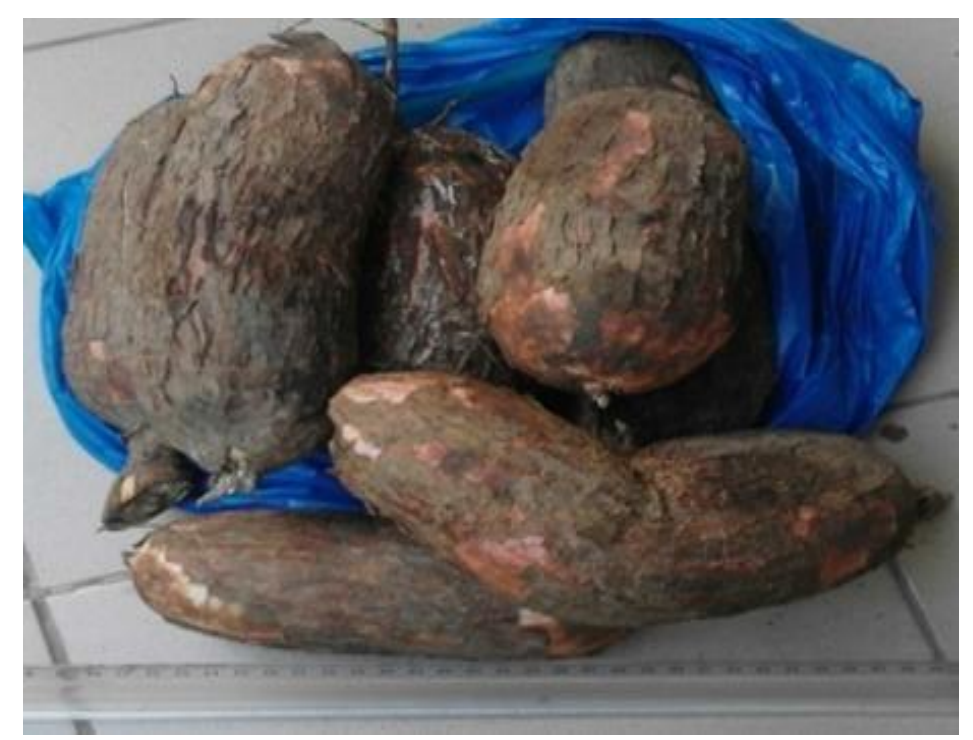


Fig.2 Diagram of bêdê production

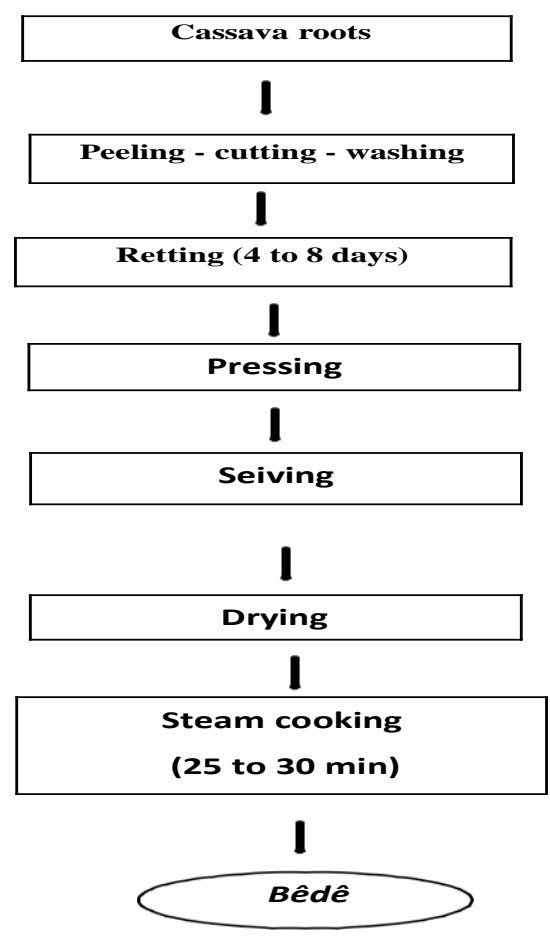

Fig.3 Peeling, cutting and washing of fresh cassava roots

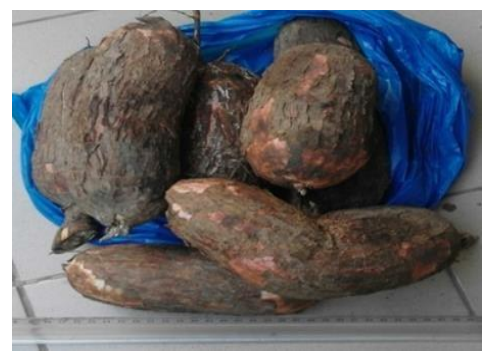

Fresh cassava roots of the sweet variety
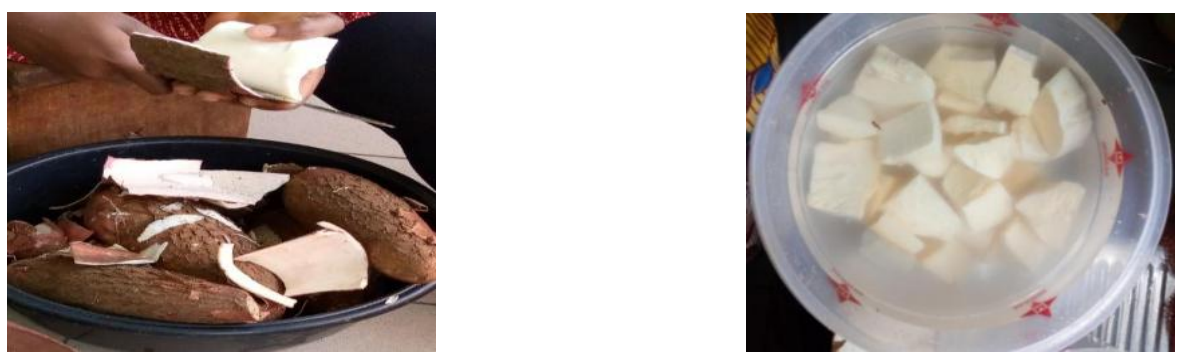

Peeling Cutting - Washing 
Fig.4 Retting of cassava cossettes after 4 and 8 days

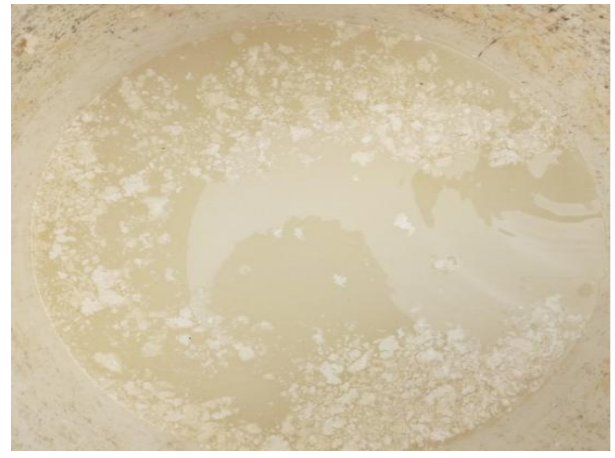

Retting

4

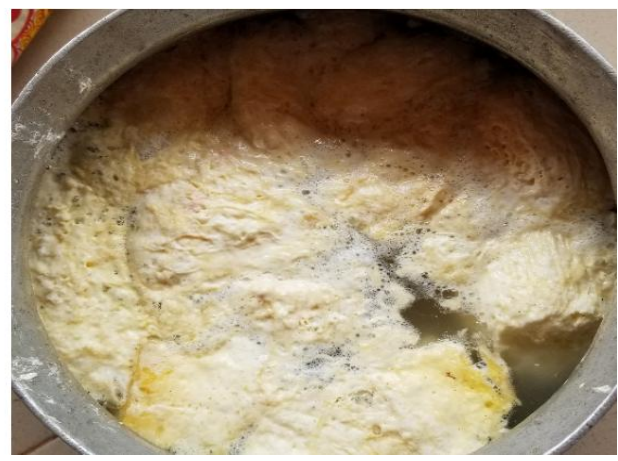

days

Retting 8 days

Fig.5 Pressing, Sieving and Drying of the cassava paste obtained after rewetting

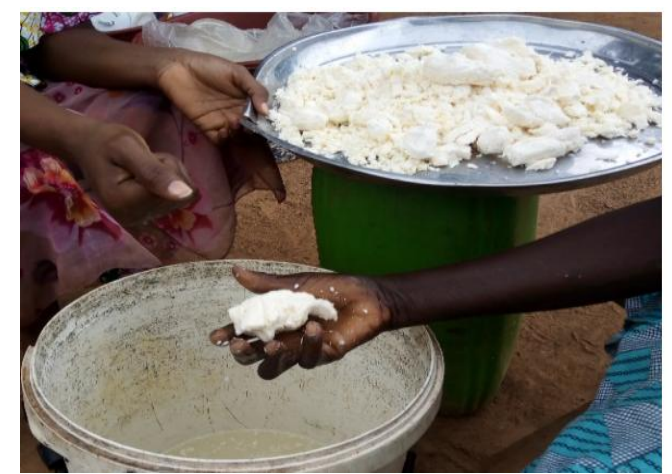

Pressing by Hand

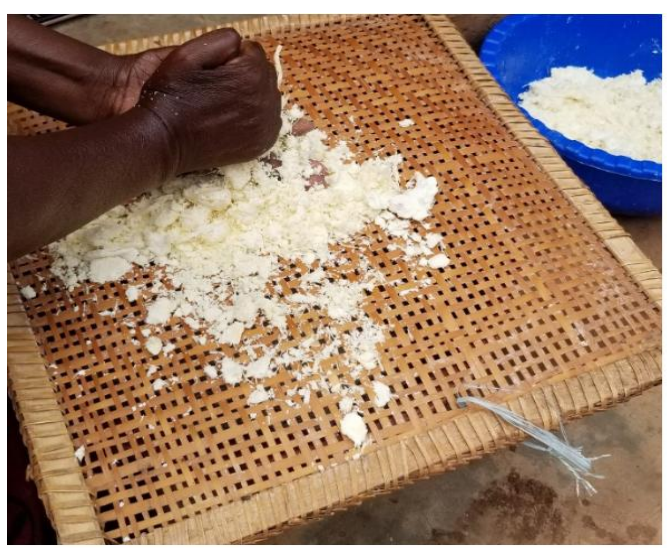

Driying

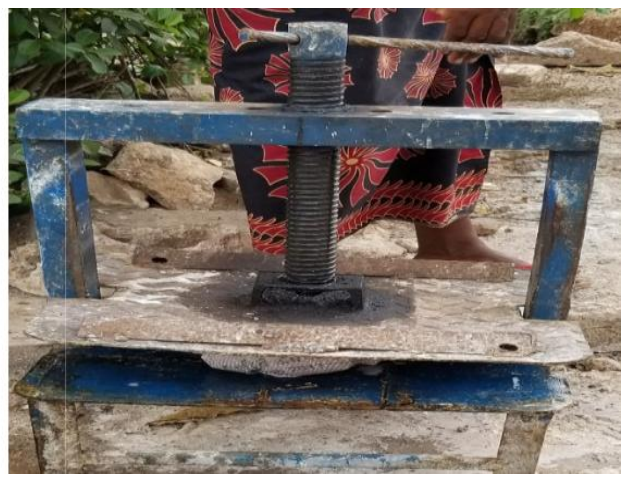

Pressing by Machine

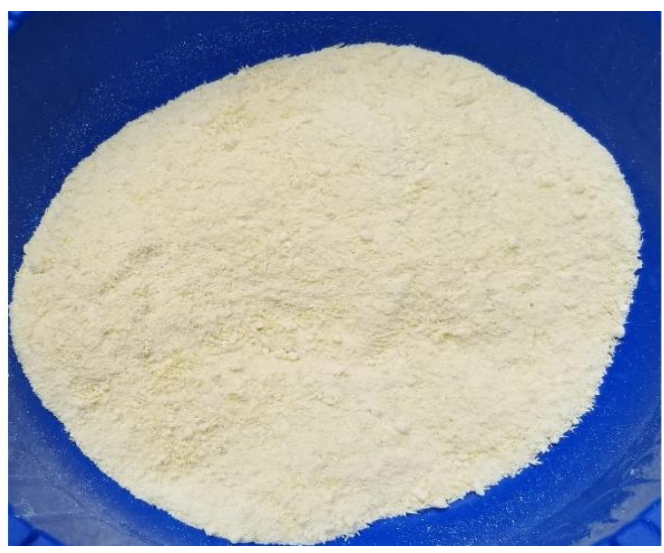

Seiving 
Fig.6 Cooking fresh bêdê granules

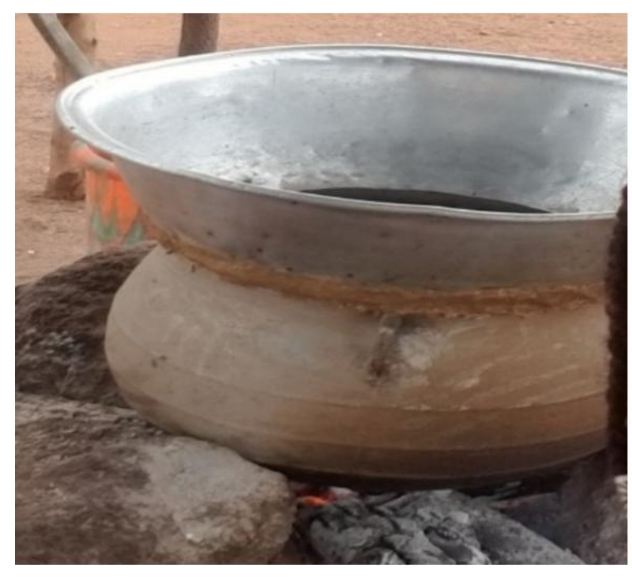

Bêdê steamed

After retting, the pieces of soft or dough cassava roots are pressed by hand or put into jute bags and pressed with a manual screw press for $30 \mathrm{~min}$ for a bag containing $10 \mathrm{~kg}$ of cassava (Figure 5). This operation removes some of the water and starch from the cassava roots, as indicated by GERES, 2013 during gari production in Benin. The cake obtained is passed over a raffia fibre sieve with variable mesh size by a circular hand movement to make the compact mass of the pressed cassava crumbly and, above all, to remove the fibres and pulp fragments that are still hard (Figure 5). The resulting semolina is dried in the sun on vans, plastic sheets or metal trays for a period ranging from a few minutes to half an hour (Figure 5). During this operation, the producer stirs the powder by hand to homogenise the drying process. This operation is also observed by Sotomey et al., (2001) during attiéké production. According to this author, this operation allows the evaporation of water as well as the elimination of cyanogenetic carbohydrates.

To finish cooking is done with steam in a device consisting of a pot containing water supporting a perforated aluminum bowl. The kettle is well nested in the perforated bowl to avoid steam leaks. It is placed on a fireplace

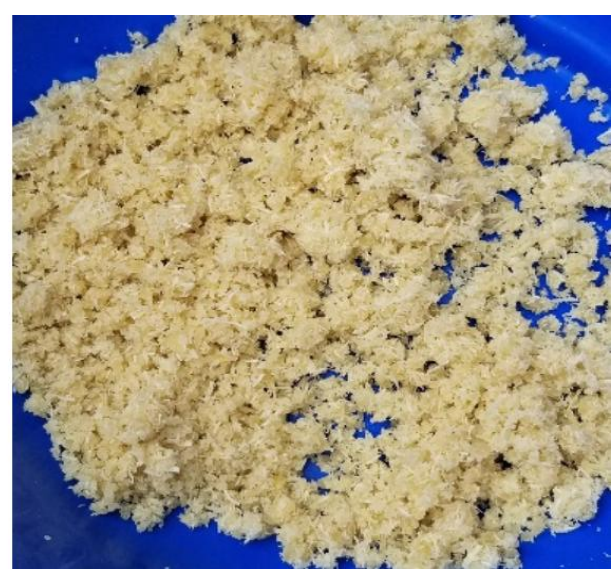

Device for cooking fresh granules of bêdê

using wood or butane gas as fuel (Figure 6). The fresh pellets from the bêdê are poured into the colander as soon as steam appears. During cooking, the semolina is occasionally turned over with a wooden or aluminium spatula. Cooking time is about 15 to 30 minutes, depending on the intensity of the fire and the amount of semolina to be cooked. Cooking promotes the removal of hydrocyanic acid, but the rate of hydrocyanic acid removal depends on the length of cooking time (Conn, 1979). Before cooking, some producers prefer to add a few ingredients such as chilli, oil, salt and even ripe banana flour to bring a particular taste to the final product because bêdê is a dish that can be eaten without accompaniment. The bêdê thus obtained comes in the form of a yellow semolina, with moist, compact grains and a lactic taste (Figure 6).

In conclusion this study aimed to establish a diagram for the production of bêdê from Côte d'Ivoire in order to facilitate its expansion nationally and internationally. The preparation of bêdê is almost manual, very long and laborious. It would be necessary to mechanize the processing stages. 


\section{Acknowledgement}

The authors are grateful the bêdê producers who freely agreed to participate in this study.

\section{Conflict of interest}

Authors have no conflict of interest regarding the publication of paper.

\section{References}

Coon, E.E. (1979). Cyanogenic glucosides. In: Neuberger, A. and Jukes, T.H. (eds.). Biochemistry of Nutrition 1A. Baltimore, University Park Press. International Review of Biochemistry, 27 (2): 21- 43.

FAO (2012). La fabrication d'une farine de manioc de haute qualité, Nigeria. Technical Centre for Agricultural and Rural Cooperation.P2

GERES (2013). Processus de production du manioc en gari au Benin. Guide manioc, P4 Louembé, D., Kobawila, S.C.,
Keléké, S., Diakabana, P., Moulassou, N.B. (2002). Rouissage des tubercules de manioc à partir de "pied de cuve" à base de manioc roui. Tropicultura, 20 (3): 118-124

N'Zué, B., Zohouri, G.P., Djédji, C., Tahouo, O. (2013). Bien cultivar le manioc en côte d'ivoire CNRA version revue et corrigée 2013.

Sotomey, M., Ategbo, E.A., Mitchikpe, E. \& Gutierrez, M.L. (2001). Innovations et diffusion de produits alimentaires en Afrique: l'attiéké au Bénin. Centre national d'études agronomiques en regions chaudes (CNEARC), 97p.

Yéboué, K.H., Amoikon, K.E, Kouamé, K.G., Kati-Coulibaly S. (2017). Valeur nutritive et propriétés organoleptiques de l'attiéké, de l'attoukpou et du placali, trois mets à base de manioc, couramment consommés en Côte d'Ivoire. Journal of Applied Biosciences 113:11184-11190.

\section{How to cite this article:}

Bouatenin Koffi Maïzan Jean-Paul, Kouame Kohi Alfred, Coulibaly Wahauwouele Hermann, Tanoh Ahou Edwige, Aka-Gbezo Solange and Dje Koffi Marcellin. 2020. Transformation of cassava into Bêdê. Int.J.Curr.Microbiol.App.Sci. 9(09): 3136-3141. doi: https://doi.org/10.20546/ijcmas.2020.909.387 